\title{
Cryopreservation of zona-hatched mouse blastocysts
}

\author{
S. E. Zhu, T. Sakurai, K. Edashige, T. Machida and M. Kasai* \\ Laboratory of Animal Science, College of Agriculture, Kochi University, Nankoku, Kochi 783, Japan
}

\begin{abstract}
Experiments were conducted to determine the conditions for successful and efficient cryopreservation of hatched mouse blastocysts, using simple vitrification procedures. Hatched blastocysts were obtained by culture of morulae in vitro. Vitrification solutions used were EFS40 and GFS40, which were $40 \%(\mathrm{v} / \mathrm{v})$ ethylene glycol and $40 \%(\mathrm{v} / \mathrm{v})$ glycerol, respectively, diluted in PBI medium containing 30\% Ficoll $(\mathrm{w} / \mathrm{v})$ and $0.5 \mathrm{~mol}$ sucrose $l^{-1}$. In the one-step method, embryos were directly exposed to the vitrification solutions at $25^{\circ} \mathrm{C}$ for 0.5 or $2 \mathrm{~min}$; in the two-step method, embryos were equilibrated with a dilute $(10-20 \%$, $\mathrm{v} / \mathrm{v}$ ) ethylene glycol or glycerol solution for 5-10 min, before a $0.5 \mathrm{~min}$ exposure to EFS40 or GFS40, respectively. They were then vitrified in liquid nitrogen. When the embryos were vitrified in EFS40, the post-warming survival rates, assessed by the re-expansion of the blastocoel during $16 \mathrm{~h}$ of culture, were higher in embryos that had hatched from the zona earlier (120-132 $\mathrm{h}$ after hCG) than in those hatched later ( $142-150 \mathrm{~h}$ after hCG); however, the highest survival rate was only $65 \%$, which was obtained by a one-step method. When embryos were vitrified in GFS40, a high survival rate (89-94\%) was obtained especially by the two-step methods. Vitrified blastocysts developed into live young just as well as did fresh blastocysts; survival was highest after transfer to recipients on day 3 or day 4 of pseudopregnancy. These findings show that hatched mouse blastocysts can be successfully cryopreserved by a simple vitrification method, and that a glycerol-based vitrification solution is more suitable than the corresponding ethylene glycol-based solution for the vitrification, probably because slower permeation of glycerol avoids toxic injury.
\end{abstract}

\section{Introduction}

Attention has concentrated on the cryopreservation of zona-intact mammalian embryos. However, the first calf derived from a frozen-thawed embryo was born from a day 10-11 blastocyst frozen after hatching from the zona (Wilmut and Rowson, 1973). The first lambs from frozen embryos were also produced from a group of embryos including hatched blastocysts (Willadsen et al., 1976). The hatched blastocyst is an especially important stage for the cryopreservation of pig embryos, because they are highly sensitive to low temperature per se (Wilmut, 1972; Polge, 1977) but they begin to acquire tolerance as they develop to peri-hatching stages (Nagashima et al., 1989). The first piglets from frozen embryos were produced from blastocysts frozen after hatching from the zona during culture (Kashiwazaki et al., 1991).

In the first pioneering work. Whittingham et al. (1972) reported that mouse embryos, at stages from the one-cell to the zona-intact blastocyst, can be deeply frozen. However, it is known that the sensitivity of embryos to cryopreservation is variable, and there have been only a few reports on the cryopreservation of mouse embryos at the stage of hatched blastocyst. Shaw et al. (1995) showed that high proportions of hatched mouse blastocysts can survive after conventional slow

*Correspondence.

Revised manuscript received 8 November 1995. freezing. However, when mouse blastocysts partially or fully hatched from the zona were frozen by a rapid method, the survival rate was lower than that of embryos at earlier stages of development (Shaw et al., 1991). Because cryobiological information for embryo storage has been most widely accumulated for mice, finding suitable conditions for the cryopreservation of hatched mouse blastocysts will contribute to the cryopreservation of embryos at this stage of other species, for example pig embryos or bovine embryos produced in vitro. Furthermore, if hatched mouse blastocysts can be cryopreserved by a simple method, it will be possible to make wide use of embryonic resources, because early stages of mouse embryos can easily develop into hatched blastocysts in culture.

As an innovative approach to cryopreservation of embryos, Rall and Fahy (1985) reported the vitrification of mouse embryos. Recently, our group developed a very simple method for the vitrification of mouse morulae, which results in virtually no decrease in viability (Kasai et al., 1990). Although the survival rate of blastocysts vitrified by this method decreased as the blastocoel enlarged (Miyake et al., 1993), we have found suitable conditions for the vitrification of zona-intact mouse blastocysts with a large blastocoel, using either an ethylene glycol-based solution (Zhu et al., 1993) or a glycerol-based solution (Zhu et al., 1994). In the present study, we report successful and efficient vitrification of hatched mouse blastocysts, based on our simple method. 


\section{Materials and Methods}

\section{Collection of hatched blastocysts}

Mature female mice of ICR colony (CLEA Japan, Inc., Tokyo) were induced to superovulate with i.p. injections of 5 iu of pregnant mares' serum gonadotrophin (PMSG) (Serotropin, Teikokuzoki, Tokyo) and 5 iu of hCG (Puberogen, Sankyozoki, Tokyo) given $48 \mathrm{~h}$ apart and were mated with ICR or C57BL/6 $\times$ DBA2 F1 hybrid male mice. At about $80 \mathrm{~h}$ after hCG injection, embryos, mostly at the morula stage, were collected from the uteri of mated animals and were pooled in a modified PBS (PBI) (Whittingham, 1971). The embryos were cultured in $0.2 \mathrm{ml}$ of a modified Krebs-Ringer-bicarbonate (KRB) medium (Toyoda and Chang, 1974) for 40-70 h under paraffin oil in a culture dish in a $\mathrm{CO}_{2}$ incubator $\left(5 \% \mathrm{CO}_{2}\right.$ in air at $37^{\circ} \mathrm{C}$ ). When embryos had expanded and hatched from the zona, they were pooled and randomly allocated into groups of about ten (7-15) embryos. In the first series of experiments, embryos were aliocated to two groups: those hatched from the zona after $40-52 \mathrm{~h}$ of culture (120-132 $\mathrm{h}$ after hCG treatment) and those hatched after $62-70 \mathrm{~h}$ of culture $(142-150 \mathrm{~h}$ after hCG treatment). In other experiments, only embryos hatched after $40-52 \mathrm{~h}$ of culture were used.

\section{Vitrification solutions}

Ethylene glycol or glycerol was diluted to $40 \%(\mathrm{v} / \mathrm{v})$ in PB1 medium containing $30 \%(\mathrm{w} / \mathrm{v})$ Ficoll 70 (average molecular

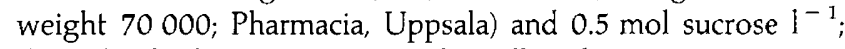
thus, the final concentrations of Ficoll and sucrose were $18 \%$ $(\mathrm{w} / \mathrm{v})$ and $0.3 \mathrm{~mol} \mathrm{l}^{-1}$, respectively. The respective vitrification solutions were designated EFS40 (Kasai ef al., 1990) and GFS40 (Tachikawa et al., 1993).

\section{Vitrification of hatched blastocysts}

Embryos were vitrified in EFS40 or GFS40 in $0.25 \mathrm{ml}$ plastic straws essentially by the procedures described by Kasai $e t$ al. (1990) and Zhu et al. (1993). Embryos were treated in a room at $25^{\circ} \mathrm{C}$.

In the one-step method, hatched blastocysts were pipetted directly into the EFS40 or GFS40 from PBI medium. They were transferred to EFS40 or GFS40 in the straw when the exposure time at this temperature was $0.5 \mathrm{~min}$, but for $2 \mathrm{~min}$ exposure, the embryos were first suspended in EFS40 or GFS40 in a watch glass, washed in the solution twice, and then transferred to the EFS40 or GFS40 in the straw. In the two-step method, embryos were equilibrated with PBI medium containing $10 \%$ or $20 \%(\mathrm{v} / \mathrm{v})$ ethylene glycol or glycerol for 5 or 10 min, transferred to the EFS40 or GFS40 in the straw, and held there for $0.5 \mathrm{~min}$.

About ten embryos were loaded into each straw containing the vitrification solution and $\mathrm{PBI}$ medium containing $0.5 \mathrm{~mol}$ sucrose $1^{-1}$ (S-PBI) as described by Kasai et al. (1990). After exposure of the embryos to the vitrification solution for 0.5 or $2 \mathrm{~min}$, the straws were placed into liquid nitrogen $(5-7 \mathrm{~cm}$ deep) in a Dewar vessel (inner diameter, $100 \mathrm{~mm}$ ). The lower part of the straw containing the embryo was immersed in the liquid, and the rest of the straw was in the cold gas vapour. After at least $1 \mathrm{~min}$, the straws were immersed in liquid nitrogen for storage.

For embryo recovery, straws were warmed rapidly in water at $25^{\circ} \mathrm{C}$. As soon as the crystallized S-PB1 medium in the straw began to melt (after about $5 \mathrm{~s}$ ), the contents of the straw were expelled either into an empty watch glass by flushing the straw with $0.8 \mathrm{ml}$ of S-PB1 medium or into a watch glass containing $0.8 \mathrm{ml}$ of S-PBI medium by pushing the cotton plug with a metal rod. The embryos were then pipetted into fresh S-PB1 medium. At $5 \mathrm{~min}$ after recovery, the embryos were transferred to fresh PB1 medium.

\section{Assessment of survival in vitro}

Embryos were washed and cultured in modified KRB medium under paraffin oil in a $\mathrm{CO}_{2}$ incubator. They were examined at $10-16 \mathrm{~h}$ and at $24 \mathrm{~h}$; the criterion for survival in vitro was re-expansion of the blastocoel (A) within $16 \mathrm{~h}$ and (B) within $24 \mathrm{~h}$ of culture. As a control, untreated hatched blastocysts were cultured after being kept in PBI medium for $30 \mathrm{~min}$ at $25^{\circ} \mathrm{C}$.

\section{Assessment of survival in vivo}

To examine the developmental potential in vivo, embryos from pigmented mice $(\mathrm{ICR} \times \mathrm{B} 6 \mathrm{D} 2 \mathrm{~F} 1)$ were used. After recovery from vitrification, embryos were cultured in KRB medium for 2-7 $\mathrm{h}$, and between four and seven re-expanded blastocysts were transferred to each uterine horn of recipient mice (8-14 embryos per animal). Recipients were pseudopregnant ICR mice that had been mated with vasectomized ICR males. Embryos vitrified in EFS40 were transferred to recipients on day $I$ to day 5 of pseudopregnancy (day 1 was the day the copulation plug was found in the morning). As a control, untreated hatched blastocysts were transferred. Embryos vitrified in GFS40 were transferred to day 3 recipients. The recipients were allowed to produce litters.

\section{Statistical analysis}

The survival rate after each treatment was compared using chi-squared tests; when the use of the chi-squared test was inappropriate, Fisher's exact probability test was used.

\section{Results}

\section{Survival of hatched blastocysts vitrified in EFS4O in vitro}

During culture of fresh mouse embryos collected at $80 \mathrm{~h}$ after hCG treatment, more than $80 \%$ hatched from the zona, about $70 \%$ of which hatched within $52 \mathrm{~h}$ of culture $(120-132 \mathrm{~h}$ after $\mathrm{hCG}$ ) and the rest hatched during $62-70 \mathrm{~h}$ of culture (142-150 h after hCG); however, no difference in morphology was observed between the quality of the two groups of embryos under a dissecting microscope. In the control where hatched blastocysts were held in PBI medium for about $30 \mathrm{~min}$ 
Table 1. Survival in vitro of hatched mouse blastocysts vitrified in EFS 40 after various treatments at $25^{\circ} \mathrm{C}$

\begin{tabular}{|c|c|c|c|c|c|c|c|c|}
\hline \multirow{2}{*}{ Treatment } & \multicolumn{2}{|c|}{ Pretreatment } & \multirow{2}{*}{$\begin{array}{c}\text { Exposure } \\
\text { time in } \\
\text { EFS40 } \\
\text { (min) }\end{array}$} & \multirow{2}{*}{$\begin{array}{c}\text { Age of } \\
\text { blastocysts } \\
(h)^{\mathrm{a}}\end{array}$} & \multicolumn{4}{|c|}{ Number of embryos } \\
\hline & $\begin{array}{c}\text { Concentration } \\
\text { of ethylene } \\
\text { glycol }\end{array}$ & $\begin{array}{l}\text { Time } \\
\text { (min) }\end{array}$ & & & Vitrified & $\begin{array}{c}\text { Recovered }^{b} \\
(\%)\end{array}$ & \multicolumn{2}{|c|}{ Survived $^{c}$} \\
\hline Control & - & - & 0 & $120-132$ & - & 124 & $123(99)$ & $123(99)$ \\
\hline (one-step) & & & & $142-150$ & 118 & $108(92)$ & $30(28)$ & $55(51)$ \\
\hline & - & - & 2.0 & $120-132$ & 118 & $103(87)$ & $16(16)$ & $30(29)$ \\
\hline & & & & $142-150$ & 101 & $91(90)$ & $7 \quad(8)$ & $26(29)$ \\
\hline \multirow{3}{*}{$\begin{array}{l}\text { Vitrified } \\
\text { (two-step) }\end{array}$} & $10 \%$ & 5 & 0.5 & $120-132$ & 113 & $103(91)$ & $60(58)^{*}$ & $79(77)^{* *}$ \\
\hline & & & & $142-150$ & 113 & $91(81)$ & $40(44)$ & $52(57)$ \\
\hline & $20 \%$ & 5 & 0.5 & $120-132$ & 114 & $92(81)$ & $47(51)^{* *}$ & $53(58)$ \\
\hline
\end{tabular}

${ }^{a}$ Time after hCG treatment required to hatch from the zona.

${ }^{\mathrm{b}}$ The straw was flushed into an empty watch glass with $0.8 \mathrm{ml}$ of S-PBI medium.

'Embryos that re-expanded during culture for $16 \mathrm{~h} \mathrm{(A)}$ and for $24 \mathrm{~h}(\mathrm{~B})$.

${ }^{\mathrm{d}}$ Percentage of recovered embryos.

${ }^{*} P<0.05,{ }^{*} P<0.01$, significantly different from the rates at a different age (142-150 h after hCG). All the survival rates after vitrification were significantly different from those of the control $(P<0.01)$.

at $25^{\circ} \mathrm{C}, 99 \%$ of the embryos either remained expanded or shrank and re-expanded during $16 \mathrm{~h}$ of culture.

Table 1 shows the survival of hatched blastocysts vitrified in an ethylene glycol-based solution (EFS40) after various treatments. In total, $87 \%$ (786/905) of the embryos were recovered after vitrification from 89 straws. In general, the survival rate, assessed by the re-expansion of the blastocoel during culture, was higher in embryos that had hatched from the zona earlier (120-132 $\mathrm{h}$ after $\mathrm{hCG})$, than in those hatched later (142-150 $\mathrm{h}$ after hCG). In the one-step method, a higher survival rate was obtained with an exposure time of $0.5 \mathrm{~min}$ rather than 2 min ( $65 \%$ versus $16 \%$, when assessed by $16 \mathrm{~h}$ of culture). However, by the two-step method, the survival rate was not improved, the rates being $51-58 \%$ when assessed during $16 \mathrm{~h}$ of culture.

\section{Survival of hatched blastocysts vitrified in EFS40 in vivo}

The optimal age of recipients for the transfer of hatched blastocysts was assessed by transferring untreated (control) and vitrified embryos to recipients on various days of pseudopregnancy. Embryos had been vitrified after direct exposure to EFS40 for $0.5 \mathrm{~min}$ at $25^{\circ} \mathrm{C}$. There was no difference in the pregnancy rate or the percentage of young produced, among the vitrified group and the control, although the proportion of young was slightly higher in the vitrified group in day 3 recipients (Table 2). When embryos were transferred on day 1 of pseudopregnancy, no recipient became pregnant. However, $50-67 \%$ of day 2 pseudopregnant recipients became pregnant and $26-39 \%$ of the embryos in the pregnant recipients developed to young. More mice became pregnant ( $83-100 \%)$ and higher proportions of embryos developed to young (40-45\%), after transfer on day 3 or 4 of pseudopregnancy for vitrified embryos, and day 4 for fresh embryos. Few recipients became pregnant (17-33\%) and the proportions of embryos that developed to young $(10-23 \%)$ were low when embryos were transferred to synchronous (day 5 pseudopregnant) recipients. In total, of 158 fresh embryos transferred into recipients that became pregnant, $45(28 \%)$ developed into live young, and of 170 cryopreserved embryos in pregnant recipients, 52 (31\%) developed into live young. Of 30 recipients that became pregnant, 27 delivered their litters. Well-developed dead fetuses were found when the three remaining mice were killed on day 23 of gestation. Of the young, in total, 29 were females and 31 were males (one was not identified) in the vitrified group, and 33 were females and 25 were males (three were not identified) in the control group.

\section{Survival of hatched blastocysts vitrified in GFS40}

In total, $96 \%(420 / 438)$ of the embryos vitrified in a glycerol-based solution (GS40) after various treatments were recovered from 42 straws (Table 3). High survival rates were obtained in both the one-step methods $(72-75 \%$, when assessed by $16 \mathrm{~h}$ of culture) and two-step methods (89-92\%). In the two-step methods, $93-97 \%$ of the embryos re-expanded at $24 \mathrm{~h}$ of culture.

Development in vivo was examined by equilibrating embryos with $10 \%(\mathrm{v} / \mathrm{v})$ glycerol for $5 \mathrm{~min}$ at $25^{\circ} \mathrm{C}$ and vitrifying them in GFS40 after exposure for $0.5 \mathrm{~min}$. In total, 72 cryopreserved embryos were transferred to six recipients, of which four became pregnant; they delivered 26 (11 female and 15 male) young in total, all being alive and normal, on days $20-21$; the proportion of young was $54 \%(26 / 48)$, when expressed on the basis of the number of embryos transferred to recipients that became pregnant. 
Table 2. Development in vivo of hatched mouse blastocysts after vitrification in EFS40

\begin{tabular}{|c|c|c|c|c|c|c|c|c|}
\hline \multirow[b]{2}{*}{ Treatment } & \multirow{2}{*}{$\begin{array}{c}\text { Day of } \\
\text { pseudo- } \\
\text { pregnancy }\end{array}$} & \multirow{2}{*}{$\begin{array}{l}\text { Number of } \\
\text { recipients }\end{array}$} & \multirow{2}{*}{$\begin{array}{l}\text { Number of } \\
\text { pregnant } \\
\text { recipients } \\
\text { (\%) }\end{array}$} & \multicolumn{2}{|c|}{$\begin{array}{c}\text { Number of embryos } \\
\text { transferred }\end{array}$} & \multicolumn{3}{|c|}{ Number of young } \\
\hline & & & & Total & To $\mathrm{PR}^{\mathrm{b}}$ & Stillbirths ${ }^{c}$ & Alive & Total $(\%)(\mathrm{T}, \mathrm{P})^{\mathrm{d}}$ \\
\hline \multirow[t]{5}{*}{ Fresh } & 1 & 6 & $0 \quad(0)$ & 82 & 0 & 0 & 0 & $0(0,-\cdots)$ \\
\hline & 2 & 6 & $3(50)$ & 66 & 28 & 1 & 10 & $11(17,39)$ \\
\hline & 3 & 6 & $3 \quad(50)$ & 63 & 37 & 3 & 10 & $13(21,35)$ \\
\hline & 4 & 6 & $6(100)$ & 71 & 71 & 10 & 22 & $32(45,45)$ \\
\hline & 5 & 6 & $2(33)$ & 68 & 22 & 2 & 3 & $5(7,23)$ \\
\hline \multirow[t]{5}{*}{ Vitrified } & 1 & 6 & $0 \quad(0)$ & 72 & 0 & 0 & 0 & $0(0,-)$ \\
\hline & 2 & 6 & $4 \quad(67)$ & 70 & 46 & 3 & 9 & $12(17,26)$ \\
\hline & 3 & 6 & $6(100)$ & 62 & 62 & 3 & 24 & $27\left(44^{*}, 44\right)$ \\
\hline & 4 & 6 & $5 \quad(83)$ & 60 & 52 & 2 & 19 & $21(35,40)$ \\
\hline & 5 & 6 & $1 \quad(17)$ & 67 & 10 & 1 & 0 & $I(1,10)$ \\
\hline
\end{tabular}

${ }^{\mathrm{a}}$ Embryos hatched within $132 \mathrm{~h}$ after hCG treatment were vitrified after direct exposure to EFS 40 for $0.5 \mathrm{~min}$ at $25^{\circ} \mathrm{C}$.

${ }^{b}$ Recipients that became pregnant.

'Including cannibalized young and dead fetuses on day 23 .

${ }^{d}$ Percentage of embryos transferred to recipients in total $(T)$ and to recipients that became pregnant $(\mathrm{P})$.

${ }^{*} P<0.01$, significantly different from control.

Table 3. Survival in vitro of hatched mouse blastocysts vitrified in GFS 40 after various treatments at $25^{\circ} \mathrm{C}^{\mathrm{a}}$

\begin{tabular}{|c|c|c|c|c|c|c|c|}
\hline \multirow[b]{3}{*}{ Treatment } & \multicolumn{2}{|c|}{ Pretreatment } & \multirow{3}{*}{$\begin{array}{l}\text { Exposure time in } \\
\text { GFS40 (min) }\end{array}$} & \multicolumn{4}{|c|}{ Number of embryos } \\
\hline & \multirow{2}{*}{$\begin{array}{l}\text { Concentration } \\
\text { of glycerol }\end{array}$} & \multirow{2}{*}{$\begin{array}{l}\text { Time } \\
(\min )\end{array}$} & & \multirow[b]{2}{*}{ Vitrified } & \multirow[b]{2}{*}{ Recovered $^{\mathrm{b}}(\%)$} & \multicolumn{2}{|c|}{ Survived $^{c}$} \\
\hline & & & & & & $A(\%)^{d}$ & $B(\%)^{d}$ \\
\hline Control & - & - & - & - & 80 & $79(99)$ & $79(99)$ \\
\hline Vitrified & - & - & 0.5 & 77 & $74(96)$ & $53(72)^{* *}$ & $63(85)^{* * *}$ \\
\hline (one-step) & - & $\ldots$ & 2.0 & 71 & $67(94)$ & $50(75)^{* *}$ & $54(81)^{* *}$ \\
\hline Vitrified & $10 \%$ & 5 & 0.5 & 73 & $70(96)$ & $62(89)^{*}$ & $66(94)$ \\
\hline \multirow[t]{3}{*}{ (two-step) } & $10 \%$ & 10 & 0.5 & 77 & $74(96)$ & $68(92)$ & $69(93)$ \\
\hline & $20 \%$ & 5 & 0.5 & 65 & $63(97)$ & $58(92)$ & $60(95)$ \\
\hline & $20 \%$ & 10 & 0.5 & 75 & $72(96)$ & $68(94)$ & $70(97)$ \\
\hline
\end{tabular}

Embryos hatched from the zona during culture for $40-52 \mathrm{~h}$ ( $132 \mathrm{~h}$ after hCG treatment) were used.

${ }^{b}$ The contents of the straw were expelled into a watch glass containing $0.8 \mathrm{ml}$ of S-PBI medium by pushing the cotton plug with a metal rod.

'Embryos that re-expanded during culture for $16 \mathrm{~h}(\mathrm{~A})$ and for $24 \mathrm{~h}(\mathrm{~B})$.

'Percentage of recovered embryos.

${ }^{*} P<0.05,{ }^{* * P}<0.01$, significantly different from control.

\section{Discussion}

After vitrification, the proportion of embryos recovered from the straw was lower $(P<0.01)$ when embryos were vitrified in EFS40 than when they were vitrified in GFS40 (87\% versus $96 \%$ ). However, this difference may not be attributable to the property of the solutions, because embryos in EFS40 were recovered by flushing whereas those in GFS40 were recovered by pushing the cotton plug. In the vitrification of zona-intact mouse blastocysts, flushing gave high recovery rates both in EFS40 (96\% 2073/2165) (Zhu et al., 1993) and in GFS40 (98\%, 1886/1930) (Zhu et al., 1994), although we did not specify the recovery rates in the previous papers. Hatched blastocysts are more likely to stick to the inner surface of the straw, and some of them may not be recovered by flushing.
The present findings show that mouse blastocysts that hatched from the zona early are more resistant to cryopreservation than those hatched later (Table 1). In bovine blastocysts produced through in vitro fertilization, it is known that blastocysts that developed early have more cells and fewer chromosomal anomalies than those developed later (Goto et al., 1992; Iwasaki, 1992); thus, in vitro fertilized bovine embryos have been cryopreserved commonly on day 7 rather than on days 8-9. The viability of delayed embryos will be low, and may be reduced further by the stress of cryopreservation.

In the vitrification of hatched blastocysts in EFS40, the maximal survival rate obtained was only $65 \%$; survival may be restricted by either intracellular ice formation due to insufficient permeation of ethylene glycol or the chemical toxicity of ethylene glycol during exposure. Considering that the maximal 
rate was obtained not by a two-step method which enables pre-permeation but by a one-step method with a brief exposure, and that the survival rate decreased with prolonged exposure $(16 \%)$, the major cause of damage seems to be the toxicity rather than the ice formation. In zona-intact mouse blastocysts, a high survival rate (92-95\%) has been obtained after vitrification in EFS40 both by a one-step method (Kasai, 1994) and by a two-step method (Zhu et al., 1993). Considering that the permeability increases as development proceeds (Mazur et al., 1976), together with the shedding of the zona pellucida, the permeation of ethylene glycol into hatched blastocysts is expected to be more rapid than that into zona-intact blastocysts. This also supports the hypothesis that hatched blastocysts are more likely to be injured by the toxicity of ethylene glycol after rapid permeation.

For the vitrification of zona-intact mouse blastocysts, both an ethylene glycol-based solution (EFS40) (Zhu et al., 1993) and a glycerol-based solution (Zhu et al., 1994) were effective, although the latter solution needed a higher concentration of glycerol $(50 \%, v / v)$. However, in this study of the vitrification of hatched mouse blastocysts, a glycerol-based solution (GFS40) was more effective than an ethylene glycol-based solution (EFS40). In the vitrification of zona-intact blastocysts in GFS40 (Zhu et al., 1994), the survival rate after one-step exposure for 0.5 min was only $25 \%$, but it increased when the exposure time was prolonged $(50 \%)$ or when pretreatment was incorporated before exposure (68-69\%). However, in hatched blastocysts, GFS40 brought relatively high survival by a one-step exposure $(72-75 \%)$, and the two-step method resulted in a much higher survival rate $(89-94 \%)$. These differences are consistent with the view that the permeability of hatched blastocysts is higher than that of zona-intact blastocysts. The previous reports on the vitrification of zona-intact blastocysts indicated that the permeation of glycerol into the cells and the blastocoel would be slower than that of ethylene glycol in the same condition, as expected from the molecular weights (Zhu et al., 1993, 1994). In sheep embryos, ethylene glycol permeates more rapidly than glycerol (Széll et al., 1989; Songsasen et al., 1995). In toxicity tests of GFS40 and EFS40 for zona-intact mouse blastocysts, GFS40 was less toxic than EFS40, survival rates after exposure for $5 \mathrm{~min}$ at $20^{\circ} \mathrm{C}$ being $58 \%$ in GFS40 (Zhu et al., 1994) and $13 \%$ in EFS40 (Zhu et al., 1993). Furthermore, we conducted supplementary toxicity tests on hatched mouse blastocysts as solution controls. When hatched blastocysts were suspended in the solutions for $5 \mathrm{~min}$ at $25^{\circ} \mathrm{C}$ and recovered without cryopreservation, survival rates assessed within $16 \mathrm{~h}$ of culture were $68 \%(34 / 50)$ in GFS40 and 6\% (3/48) in EFS40. Therefore, we conclude that, in the treatments described here, ethylene glycol permeates into hatched mouse blastocysts too rapidly and reduces survival due to its toxic action intracellularly. The slower permeation of glycerol achieves the intracellular conditions required for vitrification with less toxicity. The permeation of glycerol during pretreatment, followed by a brief exposure to GFS40, seems to be an optimal condition for vitrification.

The period during which embryos can be transferred successfully is limited. In general, maximum conception should be obtained when embryos are transferred to recipients at synchronous stages of the oestrous cycle. However, in mice, in which implantation takes place relatively early, the conception rate may be rather higher if the embryo is I day older than the recipient (McLaren and Michie, 1956). For the transfer of hatched mouse blastocysts, the synchronous stage of pseudopregnant recipient is day 5-5.5, but after transferring untreated hatched blastocysts, high rates of conception and young were obtained with recipients on day 4 , and to a lesser extent on days 2-3, but not on day 5 . In the transfer of frozen embryos, the asynchrony between recipient and embryo must be increased further, since frozen embryos require some time for the resumption of normal developmental potential (Landa, 1982; Tsunoda et al., 1982). In this study, high survival of vitrified embryos was obtained after transfer to recipients on day 3 and day 4 of pseudopregnancy, suggesting that vitrification may be less stressful than freezing.

The present study showed that mouse blastocysts after being hatched from the zona can be cryopreserved by vitrification, and that a simple method using a giycerol-based solution, rather than an ethylene glycol-based solution, is quite effective. Hatched mouse blastocysts are useful embryonic resources, and also could be a useful model for hatched blastocysts of farm animals or even of wild species.

This work was supported by grants-in-aid for scientific research from the Ministry of Education, Science, Sports and Culture, and the Ministry of Health and Welfare, Japan.

\section{References}

Goto K, Iwai N, Ichikawa K, Ishihara A, Takuma Y, Motoishi M, Tokumaru M and Nakanishi $Y$ (1992) In vitro culture of early bovine embryos produced by in vitro technique Journal of Reproduction and Development $38 \mathrm{j} 165-\mathrm{j} 17 \mathrm{I}$ (in Japanese)

Iwasaki S (1992) Studies on cytogenetic and morphological assessment of bovine embryos fertilized in vitro Journal of Reproduction and Development 38 j109-j119 (in Japanese)

Kasai M (1994) Cryopreservation of mammalian embryos by vitrification. In Perspectives on Assisted Reproduction pp 481-487 Eds T Mori, T Aono, $\mathrm{T}$ Tominaga and $\mathrm{M}$ Hiroi. Christengraf Srl, Rome

Kasai M, Komi JH, Takakamo A, Tsudera H, Sakurai T and Machida T (1990) A simple method for mouse embryo cryopreservation in a low toxicity vitrification solution without appreciable loss of viability Journal of Reproduction and Fertility 89 91-97

Kashiwazaki N, Ohtani S, Miyamoto K and Ogawa S (1991) Production of normal piglets from hatched blastocysts frozen at $-196^{\circ} \mathrm{C}$ The Veterinary Record $128 \quad 256-257$

Landa V (1982) A simplified method for freezing mouse blastocysts Folia Biologica 28 266-273

McLaren A and Michie D (1956) Studies on the transfer of fertilized mouse eggs to uterine foster-mothers Journal of Experimental Biology 33 394-416

Mazur P, Rigopoulos N, Jackowski SC and Leibo SP (1976) Preliminary estimates of the permeability of mouse ova and early embryos to glycerol Biophysical Journal $16232 \mathrm{~A}$

Miyake T, Kasai M, Zhu SE, Sakurai T and Machida T (1993) Vitrification of mouse oocytes and embryos at various stages of development in an ethylene glycol-based solution by a simple method Theriogenology $\mathbf{4 0}$ I2I-134

Nagashima H, Kato Y, Yamakawa H, Matsumoto T and Ogawa S (1989) Changes in freezing tolerance of pig blastocysts in peri-hatching state Japanese Journal of Animal Reproduction 35 130-134

Polge C (1977) The freezing of mammalian embryos: perspectives and possibilities. In The Freezing of Mammalian Embryos pp 3-18 Eds K Elliott and J Whelan. Elsevier, Amsterdam

Rall WF and Fahy GM (1985) Ice-free cryopreservation of mouse embryos at $-196^{\circ} \mathrm{C}$ by vitrification Nature $313573-575$

Shaw JM, Diotallevi $L$ and Trounson AO (1991) A simple rapid 4.5 M dimethylsulfoxide freezing technique for the cryopreservation of one-cell to blastocyst stage preimplantation mouse embryos Reproduction Fertility and Development 3 621-626 
Shaw JM, Ward C and Trounson AO (1995) Survival of mouse blastocysts slow cooled in propanediol or ethylene glycol is influenced by the thawing procedure, sucrose and antifreeze proteins Theriogenology 43 1289-1300

Songsasen N, Buckrell BC, Plante C and Leibo SP (1995) In vitro and in vivo survival of cryopreserved sheep embryos Cryobiology 32 78-91

Széll A, Shelton JN and Széll K (1989) Osmotic characteristics of sheep and cattle embryos Cryobiology 26 297-301

Tachikawa S, Otoi T, Kondo S, Machida T and Kasai M (1993) Successful vitrification of bovine blastocysts derived by in vitro maturation and fertilization Molecular Reproduction and Development 34 266-271

Toyoda $Y$ and Chang MC (1974) Fertilization of rat eggs in vitro by epididymal spermatozoa and the development of eggs following transfer Journal of Reproduction and Fertility 36 9-22

Tsunoda Y, Soma T and Sugie T (1982) Effect of post-ovulatory age of recipient on survival of frozen-thawed rabbit morulae Journal of Reproduction and Fertility 65 483-487
Whittingham DG (1971) Survival of mouse embryos after freezing and thawing Nature 233 125-126

Whittingham DG, Leibo SP and Mazur P (1972) Survival of mouse embryos frozen to $-196^{\circ} \mathrm{C}$ and $-269^{\circ} \mathrm{C}$ Science $178411-414$

Willadsen SM, Polge C, Rowson LEA and Moor RM (1976) Deep freezing of sheep embryos Journal of Reproduction and Fertility 46 151-154

Wilmut I (1972) The low temperature preservation of mammalian embryos Journal of Reproduction and Fertility 31 513-514

Wilmut I and Rowson LEA (1973) Experiments on the low-temperature preservation of cow embryos The Veterinary Record 92 686-690

Zhu SE, Kasai M, Otoge H, Sakurai T and Machida T (1993) Cryopreservation of expanded mouse blastocysts by vitrification in ethylene glycol-based solutions Journal of Reproduction and Fertility 98 139-145

Zhu SE, Sakurai T, Edashige K, Machida T and Kasai M (1994) Optimization of the procedures for the vitrification of expanded mouse blastocysts in glycerol-based solutions Journal of Reproduction and Development 40 293-300 